\title{
Current and Prospective Therapeutic Regimens for SARS-CoV-2: Review on Modern Medicine and Alternate Therapies
}

\section{Shalitha Sasi ${ }^{1}$, Sindhu Gopinathan Pillai ${ }^{1}$, Sapna Singh ${ }^{2}$, Ritu Singhal ${ }^{3}$, Lokender Kumar ${ }^{3}$, Imran H Khan ${ }^{4}$, Aarti Yadav ${ }^{5}$, Priyanka Bharadwaj $^{5}$, Prabhakar $\mathbf{M}^{5}$, Sushil Mehta ${ }^{5}$ and Suresh Thakur ${ }^{5 *}$}

${ }^{1}$ Evidentic GmbH, Martin-Buber-Str. 10, Berlin, Germany

${ }^{2}$ Safety and Analytical Research Centre (SARC) LLP, Bhat, Ahmedabad, Gujarat, India

${ }^{3}$ National Reference Laboratory and Center of Excellence (TB) WHO, Department

of Microbiology, National Institute of Tuberculosis and Respiratory Diseases, Sri

Aurobindo Marg Near Qutub Minar, Mehrauli, New Delhi, India

${ }^{4}$ Department of Pathology and Laboratory Medicine, School of Medicine University

of California, Davis, CA, USA

${ }^{5}$ NextGen In-vitro Diagnostics Pvt Ltd., BSC BioNEST Bio-Incubator Regional Centre

for Biotechnology, NCR Biotech Cluster, Haryana, India

*Corresponding Author: Suresh Thakur, NextGen In-vitro Diagnostics Pvt Ltd., BSC BioNEST Bio-Incubator Regional Centre for Biotechnology, NCR Biotech Cluster, Haryana, India.
Received: June 28, 2021

Published: July 28, 2021

(C) All rights are reserved by Suresh Thakur., et al.

\begin{abstract}
The SARS-CoV-2 virus, causative agent of the novel coronavirus disease-19 (COVID-19) continues to spread across the globe with the number of confirmed cases crossing 181 million. Rising human causalities and economic losses due to pandemic calls for a rapid development of vaccines and therapeutics. Research institutes, pharmaceutical companies and governments around the world are focused on accelerating the drug and vaccine development to contain virus and prevent further damage [1]. Many existing broadspectrum anti-viral and immune-modulatory drugs have been identified to treat disease and associated symptoms. However, their effectiveness is yet to be confirmed by randomized clinical trials. Besides, many countries are also looking into traditional medicines and herbal formulas as an adjunct therapeutic intervention. Furthermore, global race for anti-SARS-CoV-2 vaccine is ongoing, with several candidates are in use and few others progressing to phase $2 / 3$ clinical trials. Here we discuss various promising therapeutic strategies and drugs in-use and under development for treatment and management of COVID-19.
\end{abstract}

Keywords: COVID-19; SARA-CoV-2; Vaccine; Anti-viral; Alternate Medicine

\section{Abbreviations}

ARDS: Acute Respiratory Distress Syndrome; COVID-19: Coronavirus Disease-19; SARS-CoV-2: Severe Acute Respiratory Syndrome
Coronavirus 2; MERS CoV: Middle East Respiratory Syndrome Coronavirus; MoA: Mechanism of Action; RdRp: RNA Dependent RNA Polymerase; mAbs: Monoclonal Antibodies 


\section{Introduction}

The ongoing COVID-19 pandemic has put the world healthcare system at the crux of an unprecedented challenge. Majority of scientific and healthcare community is working towards finding an effective cure to fight this highly transmissible respiratory disease.

The outbreak was first reported in the Chinese province of $\mathrm{Wu}$ han in December 2019. Virus was later identified as a human betacoronavirus and officially named as the SARS-CoV-2 (Severe acute respiratory syndrome coronavirus 2) by World Health Organization [2]. Disease, termed as coronavirus disease 2019 or COVID-19, is typically presented with mild to moderate symptoms like fever, dry cough, and headache in majority of patients. However, in $20 \%$ of the infected, symptoms aggravate leading to dyspnea (shortness of breath) or hypoxia thereby requiring hospitalization. Close to $5 \%$ of patients develop pneumonia, acute respiratory distress syndrome (ARDS), respiratory failure, septic shock, or multiple organ dysfunction. Disease severity is observed mainly in elderly or in patients having underlying health conditions or co-morbidities, such as cancer, diabetes, cardiovascular disease, chronic respiratory or renal disorders. By June 2021, over 181 million cases have been reported worldwide and more than 3.9 million COVID-19 related fatalities. USA, India, and Brazil have highest number of cases at present [3].

.Current disease management protocols mainly focus on symptomatic and supportive care. Although several drugs are being evaluated to combat COVID-19, no definite prophylactic or treatment protocol has been developed yet. Extensive research is in progress focusing on antiviral drugs, cytokine inhibitors and vaccines with many candidates showing promising results. Also, in some parts of the world like China and India, traditional medicines are being considered. Here we discuss therapeutic landscape of COVID-19 drugs, vaccines and herbal medicines that are in clinical practice and/or under development. We also look at potential candidates that have been proposed for treatment of COVID-19.

\section{Virology of SARS-CoV-2 and drug targets}

SARS-CoV-2 a RNA virus with a single positive sense strand (+ssRNA) is genetically close to Severe Acute Respiratory Syndrome CoronaVirus (SARS-CoV) and Middle East Respiratory Syndrome CoronaVirus (MERS-CoV) [4]. The viral structural proteins consist of spike glycoprotein (S), envelope protein (E) and membrane gly- coprotein (M) and nucleocapsid (N) protein, which holds the RNA within the virion.

The infection is facilitated by the binding of the receptor binding domain (RBD) located in the S protein to the Angiotensin converting enzyme 2 (ACE2) target receptor on the host cell surface i.e. human airway epithelial cells and type II pneumocytes. Although lungs are the primary site of infection, the presence of ACE2 in other organs such as liver, kidneys, heart and gastrointestinal tract make them targets for SARS-CoV2. Attachment results in conformational changes leading to membrane fusion and release of RNA into the cell. The +ssRNA is directly translated to viral polyproteins that are subsequently cleaved into non-structural proteins (nsp), such as RNA-dependent RNA polymerase (RdRp) and a3C-like serine proteinase (3CLpro). These nsp proteins are required for RNA replication, translation of structural proteins, as well as inhibition of host innate immune response. The translated viral proteins are subsequently assembled to form mature virions in endoplasmic reticulum and finally released out of the cell via exocytosis [5].

\section{Host immune response}

Virions are generally transmitted through air droplets which when inhaled could cause an infection. It usually takes 2-14 days to develop symptoms and disease severity in infected patients range from mild or no symptoms to severe illness. Most of the patients present mild disease symptoms limited to upper and conducting airways, however $20 \%$ of the patients show severe symptoms including ARDS and severe inflammation [6]. COVID-19 is also reported to cause renal damage, cardiovascular problems and dysfunction of the central nervous system.

The first line of defense against SARS-CoV-2 is triggered by the activation of pathogen recognition receptors (PRRs) such as Tolllike receptors (TLR3, TLR7, TLR8) present on immune cells. They recognize pathogen-associated molecular patterns (PAMPs), such as viral RNA and damage associated molecular patterns (DAMPS) such as ATP and DNA, thereby leading to immune signaling cascades resulting in cyto-lytic responses via interferons (IFNs) and natural killer cells. Normally, within a week the adaptive immune response gets activated and viral clearance happens via specific $B$ and T cells.

\section{Antibody mediated response}

Surveys show an antibody response against the $\mathrm{N}$ protein in the early phase, followed by antibodies against the S-protein within 
4-8 days of onset of symptoms [7]. SARS-CoV2 specific IgA and IgM are detected by day 5 after infection and by day 11-14 IgG seroconversion happens. Serum IgA is detectable for a month and contributes to early viral neutralization. However, protective IgA is present in saliva and mucous secretions for approximately 3 months [8]. IgM is also responsible for the early neutralization response to the virus and the titers tend to subside after 30 days. Whereas, IgG titers remain for longer period. The longevity of serum antibody has important implications in re-infection and vaccine effectiveness.

\section{Cell mediated response}

T-cell activation majorly happens via presentation of viral structural peptides (S and N protein) by MHC-I. This in turn results in cytokine release and cytotoxic activity of CD8+ T cells, which plays a prominent role in viral clearance. The ratio of CD4/CD8 has been associated with the inflammatory response and disease severity. Moreover, studies report that presence of cross-reactive CD4+ Tcells (to common cold coronaviruses) can confer protection in uninfected individuals [9]. Most recovered patients showed a stable pool of memory CD4+ and CD8+ T cells, which contributes to protection against reinfection. CD4+ memory $\mathrm{T}$ cell can trigger B-cell and T-cell responses upon re-infection [7].

However, in geriatric patients and patients with co-morbid conditions, immune system might be weakened leading to severe form of disease. Viral load can increase quickly and infect lungs and other organs as well via systemic circulation. IFN response has been found to be impaired in many patients with severe illness. According to earlier research reports on coronaviruses, nucleocapsid (N) protein could be a suppressor for IFNs and RNA interference, enhancing viral replication capacity. Furthermore, studies reveal that in patients presenting severe symptoms, there is considerable decrease in CD4+ T cells, CD8+ T cells, and natural killer cell count. On other hand, these patients had a higher concentration of proinflammatory T cells (IL-17 producing T-helper 17), perforin and granulysin-expressing cytotoxic T cells. This usually results in hyperinflammation or a "cytokine storm" leading to plasma leakage, vascular permeability, disseminated intravascular coagulation and in some cases organ failure and tissue damage [10]. Furthermore, studies report that a decrease in regulatory $\mathrm{T}$ cell populations and memory T cells can also lead to cytokine storm [7]. Therefore, the current COVID-19 armamentarium aims at blocking the viral life cycle and enhancing host immune response.
Drug development strategies

Development of novel and specific therapeutic molecules or biologics for COVID-19 might take several years to develop. This needs to be followed by clinical trials to check for efficacy and safety of the drugs in human subjects. The current state of emergency caused by exponential rise in global cases plausible strategy is to utilize the existing drugs for COVID19. Pharmacokinetics and safety of these drugs is already well established and what remains to be evaluated is utility in COVID-19. Moreover, existing data on efficacy of different drugs for the treatment of SARS and MERS epidemics (in 2003 and 2012 respectively) does provide some insight into potential benefits and risks.

Depending on the mechanism of action (MoA), COVID therapies can be divided into following categories:

- Blocking attachment and fusion of SARS-CoV-2 to human cell receptors

- Inhibiting viral RNA replication

- Restoring host's innate immune response

- Cytokine Storm regulators

\section{Antiviral therapy}

Several small molecule drugs known to have broad-spectrum antiviral properties, as well as certain peptides and biologics are being investigated as potential anti-viral treatment. There has been considerable progress, whereby few of them have already been approved while others progressing to clinical trials. Some anti-viral drug strategies currently being explored are discussed below.

\section{Viral entry inhibitors}

\section{Chloroquine}

Chloroquine and its analog, hydroxy-chloroquine, are approved drugs for malaria and inflammatory disorders like rheumatoid arthritis and lupus. Chloroquine accumulates in acidic organelles including Golgi apparatus, which interferes with post-translational protein modifications. Hence, glycosylation of ACE2 receptor is altered and its binding affinity to viral spike protein gets affected. Another possible MoA is inhibition of post-translational modification of viral envelope glycoproteins within infected cells. However, these drugs have been reported to cause severe side effects like nausea, hypotension, and arrhythmias at higher doses. As of June 2020, WHO has recommended against use of chloroquine for treating COVID-19. 


\section{ACE-2 mimics}

Proteins and peptides that mimic ACE2 receptors prevent attachment of virus to the host cells by competitive binding. For example, APN01, a recombinant huACE2 protein initially developed by Apeiron Biologics for treatment of SARS, is now being tested for its safety and efficacy for treating COVID-19. Associated toxicities could arise due to immunogenicity and off-target binding. Similarly, several peptide mimics, such as Inhibitor 1 - 4 have been proposed to be potential drugs [11]. Recently, Saurabh and colleagues have reported that peptides mimicking alpha helix of ACE2 can block viral RBD [12].

Viral membrane fusion inhibitory peptides

During SARS outbreak in 2003, peptide drugs mimicking HR2 region in S2 domain of the spike protein were earlier designed to interrupt membrane fusion [11]. Owing to high sequence similarity of S2 unit in SARS-CoV and SARS-CoV-2, these peptides can be used for treating COVID-19. The peptides, 2019-nCoV-HR2P and EK1 have demonstrated effective fusion blockade in-vitro studies against SARS-CoV-2, however they are yet to progress to clinical trials.

\section{Viral replication inhibitors}

Nucleotide analogs

One of the most promising targets for drugs for SARS-CoV-2 is RdRp enzyme. This polymerase is highly error-prone and therefore has high chances of accepting nucleotide/nucleoside analogs thereby producing non-functional viral proteins [13]. Most used drugs in this category are Remdesivir, an adenosine analog, and Favipiravir, an adenosine and guanine leading RdRp mimic, both of which result in production of erroneous viral proteins.

\section{Protease inhibitors}

Viral proteases are viral-specific enzymes that cleave translational products to yield the functional protein. Lopinavir-ritonavir was one of the approved drugs for COVID-19, but trials have shown no clinical benefits. On the contrary, unfavorable side-effects, such as nausea, diarrhea and even respiratory failure were observed in some patients.

\section{2-deoxy-d-glucose (2-DG)}

SARS-CoV2 infected cells require an increased nutrient uptake, including glucose to facilitate rapid viral replication. 2DG, a glucose analog targets the glucose metabolism and slows down cellular glycosis, cytokine response and the overall metabolism of virus infected cells [14]. Although initially administered for cancer treatment, it has been repurposed for COVID-19 infections after several studies showed positive outcomes [1].

\section{Monoclonal antibodies}

Several neutralizing monoclonal antibodies (mAbs) developed against spike proteins of SARS-CoV-1 and MERS viruses are potential candidates for treating COVID-19. The binding sites of these antibodies overlap with motifs on SARS-CoV-2 spike protein subunits enabling neutralization effect. Another strategy being investigated issues of synthetic mAbs which are replica of mAbs derived from recovering COVID-19 patients (eg. LY-CoV555). Moreover, anti-viral antibody cocktails have also seen significant progress since it targets several viral-surface epitopes, giving an edge over mutational selection. REGN-CoV2 by Regeneron Pharmaceuticals, USA, is an example of antibody cocktail that is currently undergoing human trials. It consists of two antibodies that target separate epitopes on the spike protein.

Restoring host's innate immune response Interferons

Insufficient interferons (IFNs) in initial phases well as heightened IFN response in later stage of infection has been found to be causal factors for disease severity. Therefore, administration of IFN early-on in the infection is promising strategy to reduce the viral load and severity of infection. Different types of IFNs, including IFN alpha, beta and lambda are currently being tested for efficacy in COVID-19. Data from clinical trials till date show that among the IFN subtypes, IFN $\beta$-1b demonstrated a more favorable treatment response for COVID-19 [15,16]. One study [17] reported that IFN$\alpha 2 \mathrm{~b}$ could shorten viral shedding period. Ivan Fan-Ngai Hung., et al. reported shortened duration of viral shedding with use of IFN$\beta$-1bin combination with lopinavir and ribavirin [18]. With IFN treatment, time of intervention is very critical since IFN response in later phase of the disease can lead to excessive inflammation.

\section{Convalescent plasma}

Plasma collected from recovered patients contains neutralizing antibodies that can confer immediate protection. In a study injection of $200 \mathrm{~mL}$ of convalescent plasma was shown to reduce the viral load and improve the oxygenation levels within 3 days. Although the US FDA has conferred an Investigational New Drug (IND) status for convalescent plasma, many countries have approved or are con- 
sidering it for therapeutic use, especially for severe symptomatic patients. In addition, WHO has published guidelines for collection and safe use of convalescent plasma. Some of the pharmaceutical antiviral candidates, their mechanisms of action and manufacturers are provided in table 1.

\begin{tabular}{|c|c|c|c|}
\hline $\begin{array}{l}\text { S. } \\
\text { No }\end{array}$ & Company & $\begin{array}{l}\text { Drug } \\
\text { candidate }\end{array}$ & Description/Mechanism of action \\
\hline 1 & AIM ImmunoTech, USA & Ampligen & $\begin{array}{l}\text { Broad-spectrum antiviral for COVID-19 in Japan. A significant survival ef- } \\
\text { fect was observed in a trial evaluating mice infected with the earlier Severe } \\
\text { Acute Respiratory Syndrome (SARS) coronavirus. }\end{array}$ \\
\hline 2 & Ascletis Pharma, China & Danoprevir & $\begin{array}{l}\text { A direct-acting antiviral agent being investigated in combination with } \\
\text { ritonavir. Danoprevir is currently approved in China for the treatment of } \\
\text { chronic hepatitis C infection. }\end{array}$ \\
\hline 3 & $\begin{array}{l}\text { Ridgeback Biotherapeutics, } \\
\text { USA }\end{array}$ & EIDD-2801 & $\begin{array}{c}\text { A ribonucleosideanalog that inhibits the replication of multiple RNA vi- } \\
\text { ruses including SARS-CoV-2. The FDA has approved an Investigational New } \\
\text { Drug application (IND) to begin human clinical testing. }\end{array}$ \\
\hline 4 & Ennaid Therapeutics, USA & ENU200 & $\begin{array}{l}\text { Ennaid has revealed that ENU200 delivers specific antiviral activity against } \\
\text { 2 SARS-CoV-2 proteins, S glycoprotein and Mpro. }\end{array}$ \\
\hline 5 & Viriom, USA & Elsulfavirine & $\begin{array}{c}\text { A non-nucleoside reverse transcriptase inhibitor (NNRTI) is under inves- } \\
\text { tigation in a phase } 2 \text { trial across Russia and Eastern Europe in adults with } \\
\text { moderate manifestations of COVID-19. }\end{array}$ \\
\hline 6 & Fujifilm, USA & Favipiravir & $\begin{array}{l}\text { An antiviral agent approved in Japan for influenza treatment. Fujifilm has } \\
\text { announced the initiation of a phase } 2 \text { trial in the US in collaboration with } \\
\text { Brigham and Women's Hospital, Massachusetts General Hospital, and the } \\
\text { University of Massachusetts Medical School. }\end{array}$ \\
\hline 7 & BioCryst, USA & Galidesivir & $\begin{array}{l}\text { An adenosine nucleoside analog that acts to block viral RNA poly- } \\
\text { merase. BioCryst Pharmaceuticals has opened enrollment into a random- } \\
\text { ized, double-blind, placebo-controlled trial to assess the safety, clinical } \\
\text { impact, and antiviral effects of galidesivir in patients with COVID-19. }\end{array}$ \\
\hline 8 & AbbVie, U.S.A & Lopinavir/ritonavir & $\begin{array}{l}\text { AbbVie is collaborating with select health authorities and institutions to } \\
\text { determine the antiviral activity of the HIV drug against COVID-19. Recent } \\
\text { trial results published in the New England Journal of Medicine showed that } \\
\text { the combination therapy was not associated with clinical improvement in } \\
\text { patients with confirmed COVID-19. }\end{array}$ \\
\hline 9 & Gilead, US & Remdesivir & $\begin{array}{l}\text { Remdesivir is an investigational intravenous drug with broad antiviral ac- } \\
\text { tivity that inhibits viral replication through premature termination of RNA } \\
\text { transcription, and has in-vitro activity against SARS-CoV-2 and in-vitro and } \\
\text { in-vivo activity against related beta coronaviruses. }\end{array}$ \\
\hline 10 & Sorrento Therapeutics,USA & ACE-MAB & $\begin{array}{l}\text { A bi-specific fusion protein that binds to the spike protein of coronaviruses, } \\
\text { which is expected to block SARS-CoV-2 from binding and infecting respira- } \\
\text { tory epithelial cells or ACE2-expressing cells. }\end{array}$ \\
\hline 11 & Medin Cell, France & Ivermectin & $\begin{array}{l}\text { An FDA-approved anti-parasitic agent that has shown antiviral activity } \\
\text { against SARS-CoV-2 in vitro. MedinCell has launched a research initiative } \\
\text { on a long-acting injectable formulation of ivermectin for COVID-19. }\end{array}$ \\
\hline 12 & Regeneron, US & $\begin{array}{l}\text { Multi-antibody cocktail } \\
\text { therapy: }\end{array}$ & $\begin{array}{l}\text { Regeneron is developing a novel therapy that could potentially be adminis- } \\
\text { tered as prophylaxis before exposure to SARS-CoV- } 2 \text { virus or as a treatment } \\
\text { for those already infected. }\end{array}$ \\
\hline 13 & $\begin{array}{l}\text { Dr. Reddy's and The Defense } \\
\text { Research and Development } \\
\text { Organization (DRDO), India }\end{array}$ & $\begin{array}{l}\text { 2-Deoxy-d-glucose } \\
\qquad(2 \mathrm{DG})\end{array}$ & $\begin{array}{c}\text { 2DG is a glucose analog and has been formulated as an oral powder. It } \\
\text { targets the glycolytic pathway of viral infected cells that have an increased } \\
\text { glucose uptake. }\end{array}$ \\
\hline
\end{tabular}

Table 1: Some of the antiviral drugs under investigation. 


\section{Cytokine storm regulators}

Cytokine storm is result of an unregulated host immune response that triggers an auto-amplified production of pro-inflammatory cytokines and is one of the main causes of severity and lethality in COVID-19. It COVID-19 patients requiring intensive care are found to have high level of white blood cells, neutrophils, procalcitonin, C-reactive protein and inflammatory cytokines, especially interleukin-6 (IL6). Early diagnosis and treatment of cytokine storm syndrome is critical in saving lives as overproduction of cytokines, such as IL6, IL2, IL10, TNF and IFN-gamma, can cause tissue damage and ultimately organ failure. It is crucial that cytokine storm inhibitors be administered at correct time and dosage. If not prescribed appropriately, the immune suppression will favor viral replication. Potential cytokine inhibitors under investigation have been discussed as below.

\section{Corticosteroids}

As well established immunosuppressants corticosteroids are one of the options for the treatment of cytokine storm [19]. However, long-term side effects of corticosteroids, such as methylprednisolone and dexamethasone have been reported in earlier studies associated with other viral diseases. Nonetheless, a clinical trial in the UK reported that low doses of dexamethasone can significantly reduce mortality in COVID-19 patients on ventilators [20]. More studies are required for evaluating safety and efficacy in the context of COVID-19 Currently, the WHO and Centers for Disease Control and Prevention, USA recommends the use of systemic corticosteroids for severe and critical patients.

\section{IL-6 Inhibitors}

IL-6 blocking antibody drugs, such as Toclizumab (TCZ) have been prescribed for inflammatory diseases, such as rheumatoid arthritis (RA). Studies have shown that TCZ is positive in treating COVID-19 patients with severe cytokine storm conditions [21]. Additional studies are in progress to assess the exact timing and dosage for TCZ drugs to weigh the risk-benefit margin.

\section{Intravenous immunoglobulin (IVIG)}

IVIG is the administration of purified blood from healthy donors to achieve immune-modulation. The antibodies in blood can neutralize autoantibodies and block Fc $\gamma$ receptors (Fc $\gamma \mathrm{Rs}$ ) which helps in immune suppression. IVIG is often used as an adjunctive therapy and is a quicker option to improve treatment efficacy in severe cases.

\section{NLRP3 inhibitors}

Activation of Nod-like receptor protein 3 (NLRP3) is one of the major host-antiviral immune response. NLRP3 inflammasome protein complex induces IL-1 $\beta$ and IL-18 secretion resulting in the recruitment of natural killer (NK) cells. Augmented levels of IL-1 is suggestive of NLRP3 and therefore, NLRP3 inhibitors are a promising therapeutic approach for patients with high IL-1 expression [19]. NLRP3 inhibiting drugs like colchicine, anakinra and canakinumab are currently being investigated for their efficacy in treating COVID-19.

\section{Cyclosporin A (CsA)}

Cyclosporin is an IL-2 inhibiting drug that is usually prescribed after organ transplantation. Apart from immunomodulation, CsA also exhibits anti-viral properties by blocking viral replication [22]. However, in the case of COVID-19, meticulous clinical trials are required to confirm the clinical efficacy versus risks.

\section{BRD4 inhibitors}

Bromodomain containing protein 4 (BRD4) is responsible for NF- $\kappa \mathrm{B}$ mediated inflammatory signaling cascade. Experiments in animal models have shown that inhibition of BRD4 has anti-viral effects and can also lessen lung fibrosis, which is often observed in severe cases of COVID-19 [19]. Drugs like Apabetalone (RVX-208) and JQ-1, that can inhibit the BRD4 pathway are potential drugs that can be considered for alleviation of cytokine storm.

\section{Immune checkpoint inhibitors (ICI)}

Since COVID-19 patients express low numbers of CD8+ T-cells, there could be a deficiency in the activation of T-cells or exhaustion of T-cells. Tang., et al. suggests use of ICIs as a possible strategy to reverse this effect by activating T-cells [21]. However, no studies have been conducted yet to prove this. Numerous other candidates are under evaluation for the treatment of cytokine storm and severe symptoms like ARDS. Few of them have been covered in table 2.

\section{Vaccines}

Vaccines are identified as one of the stupendous achievements in the global health security and instrumental in the prevention and control of infectious-disease outbreaks. Clinically there are three essential factors that are crucial for developing an ideal vaccine againstSARS-CoV-2: Generation of long-lasting protective 


\begin{tabular}{|c|c|c|c|}
\hline S. No & Company & Therapeutic agent & Description \\
\hline 1 & Relief Therapeutics, Switzerland & Aviptadil (RLF-100) & $\begin{array}{l}\text { An investigational vasoactive intestinal polypeptide for } \\
\text { treatment of acute respiratory distress syndrome in } \\
\text { patients with COVI-19 infection. The drug has now en- } \\
\text { tered FDA clinical trials at Thomas Jefferson University } \\
\text { Hospital. The multicenter trial will enroll patients who } \\
\text { are already on mechanical ventilation to see if aviptadil } \\
\text { can decrease mortality in this condition. }\end{array}$ \\
\hline 2 & Innovation Pharmaceuticals, USA & Brilacidin & $\begin{array}{l}\text { A defensin-mimetic that mimics the human innate im- } \\
\text { mune system and causes disruption of the membrane } \\
\text { of pathogens, leading to cell death. It has already been } \\
\text { tested in humans in phase } 2 \text { trials for other indications. }\end{array}$ \\
\hline 3 & OncoImmune, Inc. , USA & $\mathrm{CD} 24 \mathrm{Fc}$ & $\begin{array}{l}\text { A recombinant fusion protein that fortifies an innate im- } \\
\text { mune checkpoint against excessive inflammation caused } \\
\text { by tissue injuries. OncoImmune, Inc. has received ap- } \\
\text { proval from the FDA for its phase } 3 \text { clinical trial evaluat- } \\
\text { ing the safety and efficacy of CD } 24 \mathrm{Fc} \text { for the treatment } \\
\text { of hospitalized COVID-19 patients. }\end{array}$ \\
\hline 4 & Roivant Sciences, Switzerland & Gimsilumab & $\begin{array}{l}\text { A fully human monoclonal antibody targeting granulo- } \\
\text { cyte-macrophage colony stimulating factor (GM-CSF) } \\
\text { being developed by Roivant Sciences to treat acute re- } \\
\text { spiratory distress syndrome associated with COVID-19. } \\
\text { Gimsilumab has demonstrated a favorable safety and } \\
\text { tolerability profile based on data collected to date. }\end{array}$ \\
\hline 5 & Hope Biosciences, US & HB-adMSC & $\begin{array}{l}\text { The FDA has approved a phase } 2 \text { trial evaluating the } \\
\text { efficacy and safety of Hope Biosciences' autologous, } \\
\text { adipose-derived mesenchymal stem cells (HB-adMSCs) } \\
\text { to provide immune support against COVID-19. The } \\
\text { study is expected to enroll } 75 \text { patients that are either } \\
\text { over } 50 \text { years of age, have preexisting health conditions, } \\
\text { or are at high-exposure risk. }\end{array}$ \\
\hline 7 & Leading BioSciences, US & LB1148 & $\begin{array}{l}\text { A broad spectrum serine protease inhibitor designed to } \\
\text { neutralize the activity of digestive proteases and pre- } \\
\text { serve gut integrity during intestinal distress (eg, shock, } \\
\text { infections, surgery). Leading BioSciences believes its } \\
\text { mechanism of action may limit the viral load in patients } \\
\text { with COVID-19 as the SARS-CoV-2 virus uses the ACE2 } \\
\text { receptor, which is highly expressed in the lung and GI } \\
\text { tract to infect epithelial cells of these organs }\end{array}$ \\
\hline 8 & CEL-SCI, US & LEAPS peptides & $\begin{array}{l}\text { CEL-SCI is developing an immunotherapy using a } \\
\text { patented T cell modulation peptide epitope delivery } \\
\text { technology, to stimulate protective cell-mediated T cell } \\
\text { responses and reduce viral load. }\end{array}$ \\
\hline
\end{tabular}

Citation: Suresh Thakur., et al. "Current and Prospective Therapeutic Regimens for SARS-CoV-2: Review on Modern Medicine and Alternate Therapies". Acta Scientific Microbiology 4.8 (2021): 134-150. 


\begin{tabular}{|c|c|c|c|}
\hline 9 & Kiniksa, US & Mavrilimumab & $\begin{array}{l}\text { Fully-human monoclonal antibody designed to antago- } \\
\text { nize granulocyte macrophage colony stimulating factor } \\
\text { (GM-CSF) signaling by binding to the alpha subunit of } \\
\text { the GM-CSF receptor (GM-CSFR } \alpha \text { ) }\end{array}$ \\
\hline 10 & XORTX Therapeutics, Canada & Oxypurinol & $\begin{array}{l}\text { XORTX Therapeutics is exploring the use of a new } \\
\text { formulation of oxypurinol as a novel treatment for acute } \\
\text { kidney and lung injury accompanying COVID-19 infec- } \\
\text { tion. }\end{array}$ \\
\hline 11 & $\begin{array}{l}\text { Mesoblast Limited, Melbourne, } \\
\text { Australia }\end{array}$ & Remestemcel-L & $\begin{array}{c}\text { allogeneic mesenchymal stem cell (MSC) product candi- } \\
\text { date, as a treatment for patients with acute respiratory } \\
\text { distress syndrome caused by COVID-19 }\end{array}$ \\
\hline 12 & Incyte, USA & Ruxolitinib (Jakafi) & $\begin{array}{l}\text { Incyte is initiating a phase } 3 \text { study evaluating the effi- } \\
\text { cacy and safety of ruxolitinib, a Janus kinase inhibitor, in } \\
\text { patients with COVID-19 associated cytokine storm. }\end{array}$ \\
\hline 13 & $\begin{array}{l}\text { Leukine (Partner Therapeutics) , } \\
\text { US. }\end{array}$ & Sargramostim & $\begin{array}{l}\text { Yeast-derived recombinant humanized granulocyte- } \\
\text { macrophage colony stimulating factor (rhuGM-CSF) } \\
\text { being assessed in the SARPAC trial (sargramostim in } \\
\text { patients with acute hypoxic respiratory failure due to } \\
\text { COVID-19 }\end{array}$ \\
\hline 14 & Regeneron and Sanofi & Sarilumab & $\begin{array}{l}\text { Evaluating the interleukin-6 (IL-6) receptor antagonist } \\
\text { in patients hospitalized with severe COVID-19 infec- } \\
\text { tion. The first part of the trial will evaluate the impact of } \\
\text { sarilumab on fever and patient's need for supplemental } \\
\text { oxygen, while the second part will evaluate improve- } \\
\text { ment in longer-term outcomes (ie, preventing death, } \\
\text { reducing need for mechanical ventilation, supplemental } \\
\text { oxygen and/or hospitalization). }\end{array}$ \\
\hline 15 & Jazz Pharmaceuticals, Ireland & Siltuximab & $\begin{array}{l}\text { Use of the interleukin (IL)- } 6 \text { targeted monoclonal anti- } \\
\text { body for the treatment of patients with COVID-19 who } \\
\text { have developed serious respiratory complications }\end{array}$ \\
\hline 16 & NoveomeBiotherapeutics, USA & ST266 & $\begin{array}{l}\text { A cell-free platform biologic containing hundreds of } \\
\text { anti-inflammatory proteins }\end{array}$ \\
\hline 17 & Genentech,USA & Tocilizumab & $\begin{array}{l}\text { randomized, double-blind, placebo-controlled phase } 3 \\
\text { trial in collaboration with the Biomedical Advanced Re- } \\
\text { search and Development Authority (BARDA) to evaluate } \\
\text { the safety and efficacy of the IL-6 receptor antagonist } \\
\text { plus standard of care in hospitalized adult patients with } \\
\text { severe COVID-19 pneumonia. }\end{array}$ \\
\hline 18 & Takeda, USA & TAK-888 & $\begin{array}{l}\text { anti-SARS-CoV-2 polyclonal hyperimmune globulin } \\
\text { (H-IG) being developed by Takeda for high-risk individu- } \\
\text { als with COVID-19. Pathogen-specific antibodies from } \\
\text { plasma will be collected from recovered patients (or } \\
\text { vaccinated donors in the future) and will be transferred } \\
\text { to sick patients to improve the immune response to the } \\
\text { infection and increase the chance of recovery. }\end{array}$ \\
\hline 19 & Vanda Pharmaceuticals, USA & Tradipitant & $\begin{array}{l}\text { A neurokinin-1 receptor antagonist being evaluated } \\
\text { by Vanda Pharmaceuticals for the treatment and preven- } \\
\text { tion of pneumonia associated with COVID-19. }\end{array}$ \\
\hline
\end{tabular}

Citation: Suresh Thakur., et al. "Current and Prospective Therapeutic Regimens for SARS-CoV-2: Review on Modern Medicine and Alternate Therapies". Acta Scientific Microbiology 4.8 (2021): 134-150. 


\begin{tabular}{|c|c|c|c|}
\hline 20 & TheravanceBiopharma, USA & TD-0903 & $\begin{array}{l}\text { lung-selective nebulized Janus kinase inhibitor in clini- } \\
\text { cal development to assess its utility in preventing the } \\
\text { cytokine storm associated with acute lung injury in } \\
\text { patients hospitalized due to COVID-19 }\end{array}$ \\
\hline 21 & Tiziana, USA & TZLS-501 & $\begin{array}{l}\text { The investigational therapy, being developed by Tiziana, } \\
\text { has been shown to rapidly deplete circulating levels of } \\
\text { IL- } 6 \text { in the blood, a key driver of chronic inflammation. } \\
\text { Excessive production of IL- } 6 \text { is believed to be associ- } \\
\text { ated with severe lung damage observed with COVID-19 } \\
\text { infections. }\end{array}$ \\
\hline 22 & Biohaven Pharmaceuticals, USA & Vazegepant & $\begin{array}{l}\text { An intranasal, high-affinity calcitonin gene-related } \\
\text { peptide receptor antagonist that will be evaluated in } \\
\text { the treatment of pulmonary complications of CO- } \\
\text { VID-19. Biohaven Pharmaceuticals announced that the } \\
\text { FDA has approved a phase } 2 \text { study. }\end{array}$ \\
\hline
\end{tabular}

Table 2: Ongoing efforts in development of biologics, immune-therapies and treatment for critical conditions.

antibodies against SARS-CoV-2 antigens Induction of potent T-lymphocytes, and Prevention of serious adverse events (SAEs) [23]. The current approaches being utilized to obtain the ideal vaccine against SARS-CoV-2 include conventional viral vaccines and new generation platforms, such as nucleic acid vaccines and viral vector vaccines.

\section{Virus vaccines}

The advantages of developing virus vaccines against SARSCoV-2 are that several other licensed human vaccines exist and hence infrastructure is readily available. Currently, 18 of the 102 anti-SARS-CoV-2 vaccine developers who have entered the clinical trials are utilizing this platform.

\section{Weakened/attenuated vaccine}

In these vaccines, virus is attenuated by methods, such as serial dilution, codon de-optimization or passed through series of animal or human cells until it cannot replicate efficiently to produce viral proteins but still can be recognized by human host [24]. However, there is remote possibility of weakened virus vaccine to revert to its virulent strain while replicating in the human host. Considering this challenge, extensive safety testing is required while developing this type of vaccine. A Menachery., et al. tried to develop a viable target for live-attenuated vaccineby manipulating nsp16, a conserved 20-0-methyltransferase (MTase) in combination with other attenuated strategies. Similarly, such combination attenuation approaches have also been proposed to develop anti-SARS-CoV-2 vaccine. Presently there are four developers namely, Mehmet Ali Aydinlar University/Acıbadem Labmed Health Services A.S., Codagenix/Serum Institute of India, Indian Immunologicals Ltd/Griffith University and Meissa Vaccines Inc using this approach to develop the anti-COVID-19 vaccine.

\section{Inactivated viral vaccine}

The virus is rendered as inactive by exposing the pathogen to chemicals, such as formaldehyde or heat to render it inactive. Such inactivated viruses cannot replicate in human host and contributes to a shorter period of immunity against the pathogen. Hence need for boosters is required to provide long term protection. Also, in order to make this type of vaccine, large quantities of infectious 
virus is required [25]. Besides, a study revealed that, the adverse events had developed in Rhesus macaques when inactivated SARS$\mathrm{CoV}$ vaccine was used. Hence, in order to avoid such undesired responses with potential anti-SARS-CoV-2 vaccines, it is better to utilize peptide-based vaccine than whole inactivated vaccine [26]. BBV152 (Covaxin) is developed by Bharat Biotech and is one of the example falling in this category.

Protein-based vaccines

Protein subunit

This type of vaccine is manufactured by isolating a best suited specific protein from a pathogen and presenting it as an antigen on its own to induce an immune response. However, to obtain the expected response, use of adjuvants and multiple doses are a prerequisite. Researchers using this approach to produce a vaccine against COVID-19 are focusing on the virus's spike protein or a key part of it named the receptor binding domain. At present, 33 of the 102 developers who are in the clinical phases are utilizing this technique to produce a vaccine against COVID-19 [27].

\section{Virus like particles (VLP)}

As the name suggests VLPs are used to mimic the immune response in the host. VLPs have been shown to induce a B cell mediated immune response as well as cytotoxic T- lymphocytes. This relevance caused VLPs to be chosen as a potential vaccine candidate. However, to create anti-SARS-CoV-2 vaccine, empty virus shells that mimic coronavirus structure are used. The disadvantage of this approach is that although it can elicit a strong immune response, the VLPs are difficult to manufacture.

\section{Nucleic acid vaccines}

Nucleic acid vaccines include DNA and mRNA vaccines. DNA vaccines comprise of the viral DNA which is introduced into the host membranes through electroporation to increase the uptake of DNA into the cell. In the case of mRNA vaccines, the genetic material is often encased in a lipid coat which eases the entry into the host cells. In both types, inserted nucleic acid promotes protein synthesis which is expected to elicit a humoral and cell-mediated response like the infection that occurs naturally. Nucleic acid platform allows antigen manipulation and aids speed of production since the manufacturing can be performed artificially and produced cell-free, thereby allowing the manufacturing to by-pass the need for biosafety lab-2 (BSL-2). However, licensed vaccines using this platform are currently unavailable for any reference.
Cadila's candidate for the vaccine, known as ZyCov-D is a DNA based vaccine whereas Moderna mRNA-1273 is a novel mRNAbased lipid nanoparticle (LNP)-encapsulated vaccine that synthesizes SARS-CoV-2 full length prefusion stabilised spike (S) protein. BNT162b2 is also a potential vaccine for COVID-19 formulated by BioNTech and Pfizer. This is an RNA vaccine consisting of nucleoside-modified mRNA expressing a mutated form of SARS-CoV-2 spike protein and is embodied in lipid nanoparticles.

\section{Viral-vector vaccines}

This technology is used to develop vaccine, which involves delivery of one or more genes that encode a target antigen, within a recombinantly engineered virus. The two types of viral-vector vaccines are (i) Replicating viral vector, and (ii) Non-replicating viral vector. The replicating viral vector method utilizes live-attenuated virus that can replicate in the host cells hence the vaccine can elicit a safer and stronger immune response. On the other hand, the nonreplicating viral vector vaccine utilizes inactivated virus unable to replicate in the host cells. This non-replicating viral vector technology has been proven useful in gene therapy, but no licensed vaccines are available in this technique. Also, booster doses might be required to acquire the expected immune response if this process is implemented. For both types of viral vector-based vaccines, the host's existing immunity against the vectors can mitigate the vaccine's effectiveness. Excellent preclinical and clinical data are available for many emerging viruses for vaccines for this platform and no infectious virus needs to be handled. Examples of viral vectors used are adenovirus (Ad), measles virus (MV), vesicular stomatitis virus (VSV), alphaviruses, poxviruses, and herpesviruses $(24,1)$. Such viral vectors have been utilized to develop vaccines against viral diseases such as rabies, ebola, smallpox, monkeypox. Also, some studies have recently shown positive signs to help develop efficacious vaccines against HIV, tuberculosis (TB), Human cytomegalovirus (HCMV) infection and many more [28].

ChAdOx1 nCoV-19 or AZD1222 is a replication deficient adenovirus-vectored chimpanzee $(\mathrm{Ch})$ vaccine $(\mathrm{Ad})$ encoding the fulllength SARS-CoV-2 spike protein along with tissue plasminogen activator (tPA), that was developed by the University of Oxford [29]. It has been shown to be effective against nCoV-19, the novel coronavirus first described in 2019. Trade-named Sputnik V or GamCOVID-Vac is an anti-SARS-CoV-2 vaccine candidate constituted by the Institute of Epidemiology and Microbiology of Gamaleya Study. Gam-COVID-Vac is a human adenovirus viral two-vector vaccine, 
a common cold virus, fused with gene that encodes SARS-CoV-2 spike protein to induce an immune response. The type-5 (Ad5) recombinant adenovirus and type-26 (Ad26) adenovirus are used as vectors in the vaccine. On first day the Ad26-based vaccine is used and the Ad5 vaccine is used on the $21^{\text {st }}$ day to improve response.

As of May, 2021, WHO has updated and released a draft stating the names of competing vaccine developers, diverse vaccine platforms and corresponding vaccine candidates, number and timing of the doses, route administration and status of the clinical stages [30]. 102 candidates have entered human clinical trials and 184 are in pre-clinical evaluation stage. Table 3 lists some of the vac- cines that have entered phase 3 clinical trials and phase 4. Among these Pfizer/BioNTech vaccine has been approved in Saudi Arabia, Bahrain and Switzerland, and authorized for emergency use in the U.S and other. Subsequently the Moderna vaccine has also been authorized for emergency use in the Unites States, Israel, Switzerland and United Kingdom. Other potential vaccine candidates in the phase 4 such as AstraZeneca-University of Oxford's ChAdOx1, also known as Covishield, has been authorized for emergency use in United Kingdom, Argentina and India. Others such as Covaxin and CoronaVac have been granted emergency usage primarily in India and China respectively, while BBIBP-CorV has been approved in China and United Arab Emirates.

\begin{tabular}{|c|c|c|c|c|c|c|}
\hline $\begin{array}{l}\text { S. } \\
\text { No }\end{array}$ & Developer & $\begin{array}{l}\text { Vaccine Plat- } \\
\text { form }\end{array}$ & $\begin{array}{l}\text { Type of vaccine } \\
\text { candidate }\end{array}$ & Authorized Use & $\begin{array}{c}\text { Clinical } \\
\text { Trial } \\
\text { Status }\end{array}$ & $\begin{array}{l}\text { No. Of } \\
\text { doses }\end{array}$ \\
\hline 3 & University of Oxford, UK & $\begin{array}{l}\text { Non-replicating } \\
\text { viral vector }\end{array}$ & ChAdOx1 & $\begin{array}{l}\text { Emergency use in the United } \\
\text { Kingdom, India and Argentina }\end{array}$ & Phase 4 & $1-2$ \\
\hline 4 & Gamaleya Research Institute & $\begin{array}{l}\text { Non-replicating } \\
\text { viral vector }\end{array}$ & $\begin{array}{c}\text { Adeno-based } \\
\text { (rAd26-S+rAd5-S) }\end{array}$ & $\begin{array}{l}\text { Emergency use in Russia, } \\
\text { Belarus, Argentina, Algeria, } \\
\text { Bolivia, the Palestinian } \\
\text { Authority and Serbia }\end{array}$ & Phase 3 & 2 \\
\hline 5 & $\begin{array}{l}\text { CanSino Biological Inc./ Beijing } \\
\text { Institute of Biotechnology }\end{array}$ & $\begin{array}{l}\text { Non-replicating } \\
\text { viral vector }\end{array}$ & $\begin{array}{c}\text { Adenovirus Type } 5 \\
\text { Vector }\end{array}$ & Limited use in China & Phase 4 & 1 \\
\hline 6 & $\begin{array}{c}\text { Janssen Pharmaceutical } \\
\text { Companies }\end{array}$ & $\begin{array}{l}\text { Non-replicating } \\
\text { viral vecto }\end{array}$ & Ad26COVS1 & Emergency use in USA & Phase 3 & $1-2$ \\
\hline 7 & Sinovac & Inactivated & Inactivated & $\begin{array}{c}\text { Emergency use in China and } \\
\text { Indonesia }\end{array}$ & Phase 4 & 2 \\
\hline 8 & $\begin{array}{l}\text { Wuhan Institute of Biological } \\
\text { Products/Sinopharm }\end{array}$ & Inactivated & Inactivated & Limited Use in China and UAE & Phase 3 & 2 \\
\hline 9 & $\begin{array}{l}\text { Beijing Institute of Biological } \\
\text { Products/Sinopharm }\end{array}$ & Inactivated & Inactivated & $\begin{array}{l}\text { Approved in China, UAE and } \\
\text { Bahrain. } \\
\text { Emergency use in Egypt and } \\
\text { Jordan }\end{array}$ & Phase 3 & 2 \\
\hline
\end{tabular}

Table 3: COVID19 vaccines that are in Phase 3 and 4. 
Adverse effects

As we are writing this review, billions of people across the globe are being vaccinated with different vaccines available. Regulatory authorities such as FDA, CDC etc around the world are constantly monitoring the safety of the COVID-19 vaccines. Based on reports submitted to Vaccine Adverse Event Reporting System (VAERS), a type of severe allergic reaction-anaphylaxis-was observed in approximately 2 to 5 people per million vaccinated in the United States. But it is a rare effect and almost always occurs within 30 minutes after vaccination. Nevertheless, effective medications are available to immediately treat patients who experience anaphylaxis following vaccination. In early March 2021, there were few reports on blood clots in a number of people following the OxfordAstraZeneca vaccine. Two deaths have been reported in Europe linked to this vaccine. However, upon further investigation by European Medicines Agency (EMA) and WHO's safety group it was concluded that there is no overall increase in thromboembolic events and the vaccine is safe to use. These developments have also prompted the authorities to educate all the health providers and general public on how to recognize serious adverse effects and how to enable treatment immediately. To date, VAERS has not detected significant patterns in cause of death that would indicate a safety problem with COVID-19 vaccines (CDC).

\section{Traditional medicines}

Several countries have a long history of traditional medicines and herbal therapies that play an important role in preventive and protective care against infections. Natural products and their derivatives have shown to be effective against viral infections. Having said that, when herbal drugs are used to target a novel disease like COVID-19 in amalgamation with other antivirals, antibiotics and immune suppressants, safety and efficacy must be evaluated before its application. Currently, there are no requisite studies on the development of anti-COVID-19 drugs from herbal resources [31]. Yet numerous diseases in humans have been treated with herbal medicines for ages and the benefits they provide cannot be ignored.

\section{Traditional chinese medicines (TCM)}

Luo., et al. reports that by combining both TCM and western medicine, China has achieved good clinical efficacy [32] in the prevention and control of the pandemic and the result was appreciated by the WHO. Since the pandemic was declared, the National Health Commission (NHC) of the People's Republic of China has successively issued seven versions of Diagnosis and Treatment Protocol for COVID-19. The TCM therapy was recommended in Trial Version 3.

Currently, according to TCM, pathogenesis of COVID-19 are dampness, toxin, heat, and stasis ranging from the period of disease onset to critical stage. Hence, therapeutic principles dispelling cold, relieving exterior, dissipating phlegm, clearing away heat, invigorating spleen, and replenishing "Qi” (energy flow) were applied [33]. Eventually, based on the clinical experience of pandemic prevention and control: JinhuaQinggan Granule, LianhuaQingwen Capsule, Xuebijing Injection, QingfeiPaidu Decoction, HuashiBaidu Formula, and XuanfeiBaidu Formula, collectively referred to as "Three TCM prescriptions and three medicines", has resulted in a group of effective therapeutics in combination with western medicines against COVID-19 in China [32]. The table 4 summarizes the hallmarks of the three TCM prescriptions and three medicines.

Further analysis also revealed that in the "Three TCM prescriptions and three medicines" all except Xuebijing injection consists of Maxing Ganshi decoction (MXGSD). Five Chinese herbs are frequently applied in these formulations, which includes: (i) Guanghuoxiang (PogostemonisHerba), (ii) Gancao (Glycyrrhizae Radix etRhizoma), (iii) Shigao (Gypsum Fibrosum), (iv) Kuxingren (Armeniacae Semen Amarum) and (v) Mahuang (EphedraeHerba).

\section{Traditional Indian medicines}

One of the oldest treatments that exists in human history is the Indian traditional medicine. Thus, Ayurveda, Siddha, Unani and Yoga, Naturopathy, and Homeopathy play a relevant role in treating diverse diseases [34]. Epidemic management exists in the classic Ayurveda text "CharakaSamhita" and describes the importance of boosting immunity to prevent and arrest the disease progression to maintain homeostasis [35]. Many studies about anti-coronavirus activity using medicinal plants have been conducted in India since a lot of Indian medicinal plants exhibit antiviral activities [34]. A study by Vimalanathan., et al. has shown medicinal plants namely Indigofera tinctoria (A0), Vitextrifolia, Gymnemasylvestre, Abutilon indicum, Leucasaspera, Cassia alata, Sphaeranthusindicus, Clitoriaternatea, Clerodendruminerme Gaertn, Pergulariadaemi and Evolvulusalsinoides have anti-coronavirus activity in mouse [36]. Table 5 shows some promising medicinal plants which needs to be studied further apropos to COVID-19. 


\begin{tabular}{|c|c|c|c|c|}
\hline Sl. No. & Medicine & $\begin{array}{c}\begin{array}{c}\text { Effect on the clinical } \\
\text { symptom }\end{array} \\
\end{array}$ & Active components & MOA/key targets \\
\hline 1 & JinhuaQinggan Granule & $\begin{array}{l}\text { Mild fever, cough, fatigue, ex- } \\
\text { pectoration, Relieve the } \\
\text { psychological anxiety of } \\
\text { patients }\end{array}$ & $\begin{array}{c}\text { Kaempferol, baicalein and } \\
\text { oroxylin A }\end{array}$ & $\begin{array}{c}\text { ACE2, PTGS2, BCL2, } \\
\text { CASP3, HSP90AB1, } \\
\text { HSP90AA1, PTGS1 and } \\
\text { NCOA2 } \\
\end{array}$ \\
\hline 2 & $\begin{array}{l}\text { LianhuaQingwen } \\
\text { Capsule }\end{array}$ & $\begin{array}{c}\text { Regulation on immunity } \\
\text { functions, and inhibitory } \\
\text { effects on virus replication and } \\
\text { pro-inflammatory cytokines } \\
\text { release. }\end{array}$ & $\begin{array}{l}\text { Chlorogenic acid, caffeic acid, } \\
\text { isochlorogenic acid B, } \\
\text { isochlorogenic acid C, phillyrin, } \\
\text { forsythiaside A, and rutin }\end{array}$ & $\begin{array}{c}\text { attenuated the } \\
\text { SARS-COV-2 replication } \\
\text { in vitro }\end{array}$ \\
\hline 3 & Xuebijing Injection & $\begin{array}{l}\text { Regulate the immune function } \\
\text { of patients improve the } \\
\text { condition of sepsis }\end{array}$ & $\begin{array}{c}\text { Safflor yellow A, ligustrazine, } \\
\text { ferulic acid, salvianic acid A, } \\
\text { paeoniflorin, and } \\
\text { protocatechualdehyde. }\end{array}$ & $\begin{array}{l}\text { regulation of } 70 \text { proteins } \\
\text { that interact with ACE2 }\end{array}$ \\
\hline 4 & QingfeiPaidu Decoction & $\begin{array}{l}\text { Inflammatory response, } \\
\text { modulate immune function, } \\
\text { reduce lung injury, and protect } \\
\text { nerve function }\end{array}$ & $\begin{array}{l}\text { Quercetin, luteolin and } \\
\text { kaempferol }\end{array}$ & $\begin{array}{c}\text { AKT1, JUN, MAPKs, IL-6, } \\
\text { RELA, STAT1 }\end{array}$ \\
\hline 5 & HuashiBaidu & $\begin{array}{l}\text { Severe epidemic toxin blocking } \\
\text { the lung syndrome }\end{array}$ & Baicalein and quercetin & $\begin{array}{l}\text { MAPK3, MAPK8, TP53, } \\
\text { CASP3, IL6, TNF, MAPK1, } \\
\text { CCL2, PTGS2, }\end{array}$ \\
\hline 6 & XuanfeiBaidu & $\begin{array}{l}\text { Suppresses the inflammatory } \\
\text { storms and excessive activation } \\
\text { of immune response }\end{array}$ & $\begin{array}{l}\text { Luteolin, beta-sitostero, } \\
\text { formononetin, and shinptero- } \\
\text { carpin }\end{array}$ & $\begin{array}{l}\text { IL-6, chemokines CXCL8, } \\
\text { etc., and related T cells } \\
\text { (Th17, Th1, Th2) }\end{array}$ \\
\hline
\end{tabular}

Table 4: Chinese medicines for COVID19.

\begin{tabular}{|c|c|c|}
\hline Medicinal plants & Activity & References \\
\hline Vitextrifolia & \multirow{2}{*}{$\begin{array}{c}\text { Decrease the } \\
\text { inflammatory } \\
\text { cytokine level using } \\
\text { the NF-kB pathway }\end{array}$} & \multirow[b]{3}{*}{$\begin{array}{c}\text { Tiwari and Khosla } \\
2009 \text { [44] }\end{array}$} \\
\hline Sphaeranthusindicus & & \\
\hline Clitoriaternatea & $\begin{array}{c}\text { ADAM17 } \\
\text { metalloproteinase } \\
\text { inhibitor which is } \\
\text { involved in ACR } \\
\text { shredding }\end{array}$ & \\
\hline Glycyrrhizaglabra & \multirow{2}{*}{$\begin{array}{l}\text { Inhibit SARS-CoV } \\
\text { replication }\end{array}$} & \multirow{3}{*}{$\begin{array}{l}\text { Keyaerts., et al. } \\
2004 \text { [45] }\end{array}$} \\
\hline Allium sativum & & \\
\hline $\begin{array}{l}\text { Clerodendrum inerme } \\
\text { Gaertn }\end{array}$ & Inhibit viral ribosome & \\
\hline $\begin{array}{l}\text { Coriandrumsativum, } \\
\text { Boerhaaviadiffusa, } \\
\text { Cynarascolymus, } \\
\text { Cosciniumfenestratum, } \\
\text { Punicagranatum Cassia } \\
\text { occidentalis and } \\
\text { Embeliaribes }\end{array}$ & Inhibit ACE & $\begin{array}{l}\text { Hussain., et al. } \\
2018 \text { [46] }\end{array}$ \\
\hline
\end{tabular}

Table 5: Potential traditional Indian herbs for treatment of COVID19.
Other medicinal plants, such as Acacia nilotica, Eugenia jambolana and Euphorbia granulate have also displayed inhibitory effect on HIV protease and these plants can be considered as potential drug candidates for COVID-19. It has also been suggested that plants, such as Ocimum sanctum, Ocimumkilimandscharicum, Solanumnigrum and Vitexnegundo that have inhibitory effect on reverse transcriptase of HIV can be investigated for SARS-CoV-2 as well [31].

In short, there exists a plethora of potential medicinal plants in India, but further investigations are required to design and develop a drug specific to SARS-CoV-2. The Ministry of AYUSH, under the Government of India is responsible for the development of indigenous alternative medicine. Currently, 7 Ayurveda and 1 Siddha based clinical trials are conducted in collaboration with Ministry of AYUSH(MOA). These trials are investigating the immune-modulatory properties of various ayurvedic preparations including Amalaki (Emblica officinalis), Ashwagandha (Withania somnifera) and Guduchi (Tinospora cordifoloia). Some of the trials are also looking into the combined effect of ayurvedic interventions followed by homeopathy or siddha. 
Other herbal remedies

Several other traditional medicines including Iranian, Korean and African are being tested for their potency against SARS-CoV-2. A study by Ziai and Heidari [37] found 20 Iranian herbal extracts namely Cerasusavium (L.) Moench, Alceadigitata (Boiss.) Alef, and Rubia tinctorum L, Citrus aurantium L.; Berberisintegerrima Bge; PeganumharmalaL and Allium sativum L that exhibited ACE inhibitory effects. Aretmisiaannua, a herb used in Iranian and African medicines has been recognized by WHO as an ideal drug candidate for the treatment of COVID-19 [38].

In addition to this having Vitamin $\mathrm{C}$ rich fruits and drinks can be considered as a potential home remedy. Early clinical trials have shown that Vitamin C or ascorbic acid has antioxidant properties and can inhibit cytokine surge [39].

\section{Effect of yoga and breathing exercise}

For consideration of SARS-CoV-2 infection and COVID19 treatment and/or prevention, certain complementary activities of seated meditation, yoga asanas (postures), and pranayama (breathing) with relevance to immune function have been focused in various studies. Yoga and pranayama help to reduce the incidence, including adverse effects and sequelae, of COVID-19 disease. Anti-stress and anti-inflammatory effects are a few of the mentioned beneficial activities associated with meditation, yoga asanas, and pranayama practices. Studies have found yoga and meditation have immune effects related to improving lung health, and reducing the vulnerability of viruses and improving acute respiratory infections.

Several clinical trial studies have shown that yoga has an incredible impact on enhanced pulmonary output in patients suffering with chronic obstructive pulmonary disease (COPD), a significant cause of morbidity and mortality, and is a serious public health concern. The beneficial effects seen in patients doing yoga, such as expansion in pulmonary stamina, healing chest muscles, widening of lung capacity, increasing levels of energy and refreshing the body.

The patients experienced a loss in the elements of panic and anxiety, breaking the vicious loop of aggravating bronchial obstruction. On the basis of several significant benefits of yoga on the immune and respiratory systems against various clinical environments, including contagious diseases, discussed above, we pre- sume the therapeutic benefits of yoga for the care and mitigation of COVID-19.

\section{Conclusion}

In the wake of this pandemic healthcare infrastructure had been divested of basic resources and amenities including hospital beds, ventilators, diagnostic kits, medicines, and personal protective equipment. Over the course of the pandemic, clinicians and public have learnt to cope with the changes and implement preventive measures as a part of the daily routine. Healthcare systems are slowly adapting to new treatment regimens and therefore better management of COVID-19 cases is becoming possible.

Nevertheless, effective and specific therapeutic drugs are still the need of the hour to ensure lowering of mortality rates and affordable vaccines are required to bring down the numbers and prevent the disease One of the major challenges in the drug and vaccine development pipeline is limited sample size for clinical trials and geographically biased data. Moreover, mutations can lead to distribution of high genomic variability across the globe. Most of the observed mutations are single-nucleotide polymorphisms (SNPs) compared to in/del (insertion/deletion) events thereby largely maintaining the viral genomic integrity [40]. However, diagnostics, drug and vaccine designs, especially DNA and RNA vaccines should take into consideration these mutational events. The new strain that emerged in UK in December 2020, also known as the B.1.1.7 or SARS-CoV-2 VUI202012/01 strain has been found to be more infectious than the other strains. The new strain has been identified to carry 14 mutations, of which mutation N501Y and $\mathrm{P} 681 \mathrm{H}$ in the RBD region and deletion of amino acid $\mathrm{H} 69$ and V70 in the $\mathrm{S}$ gene could be of biological significance. This could impact PCR diagnostics if the target is only the viral S-gene. However, at this point of time there is no concrete evidence to support that the VUI202012/01 strain can cause increased severity of infection or affect antibody response or vaccine efficacy. In addition, the SARSCoV-2 501Y.V2 strain that was recently reported in South Africa, has nine mutations in the spike protein, which includes three substitutions in the RBD and four substitutions and a deletion in the $\mathrm{N}$-terminal domain [41]. A Brazilian strain with similar mutations has also been reported. These mutations were reported to confer resistance to monoclonal antibody therapy and convalescent plasma therapy, which could have implications in COVID-19 reinfection and vaccine potency if spread globally [41]. Recently, the Indian 
double mutant (B.1.617) that appeared during the deadly second wave in India, have been identified as a mutant of concern by the WHO. This mutant has also shown high transmissibility and resistance to antibody neutralization [42].

Apart from the success of finding a potent therapeutic agent against COVID-19, other difficulties, such as mass production, distribution, storage and delivery and administration also need to be worked out. To expedite the COVID-19 therapeutics research and development, several regulatory authorities including the US FDA has relaxed rules for new drug application and clinical trials. As we conclude this review, several vaccines are being authorized and granted approval for emergency use globally. With the current pace, we can expect successful vaccination drives for the public by 2021-2022. However, regulatory bodies should emphasize on multiple randomized trials and proper scientific validation to ensure safety and efficacy of all vaccine production batches.

\section{Future Directions}

One of the main reasons that led to the global spread of SARSCoV2 is the presence of asymptomatic and mild infections. These people became carriers and super-spreaders. And this makes it very difficult to track, trace and control movements of infected persons.

On the therapeutic front, the heterogeneity of disease outcomes within age groups and similar vulnerable groups makes it challenging to define a singular mode of treatment. COVID-19 can also result in secondary infections in some patients, leading to complications. For example, the deadly black fungus (Mucormycosis) infections were reported in India among COVID-19 patients with diabetes and other co-morbidities, who were under immunosuppressants and corticosteroids. Another line of research investigates the genetic underpinning the geographical variations in disease outcomes. Interestingly, lower COVID-19 mortality rates were recorded in developing countries compared to that of developed nations, suggesting a clear genetic advantage. A positive correlation is shown between improved hygiene and higher incidence of autoimmune disorders and Covid-19 severity [43]. This could possibly be linked to the "hygiene hypotheses" and implications of the role of microbiome in immune training. Thus, microbiome therapies can be considered in the battle against COVID-19.

Adding to the complexity, concerns over mutations and durability of protective immune response has risen. A recent study by
Wheatly., et al. indicates that immunity after natural infection might just confer transient protection to re-infection based on their data of memory $b$ and $T$ cell population in recovered patients [9]. Therefore, SARS-CoV-2 vaccines must possess greater immunogenicity and durability to steer long-term protection. Moreover, the SARSCoV-2 virus is evolving and studies on the spread of new variants and re-infection in vaccinated individuals by new variants is yet to come into light. Hence, WHO has advised prudence against the new emerging variants which has now been confirmed in several countries [41] though more evidence is required to evaluate their true virulency and the perils associated with it is imperative to take precautions, practice personal hygiene and maintain social distancing at all times. The key is to lower mutation rates by slowing down the transmissions and decreasing the infection rates across the globe. A new potent mutant could have severe implications on vaccinations, re-infection and herd-immunity, possibly triggering a new wave of pandemic. Moreover, vaccination does not imply hundred percent safety. Vaccinated people can be carriers of the virus and can be super-spreaders. Hence until a substantial percentage of the population has been vaccinated, the governments must not ease restrictions and social distancing must be practiced. Furthermore, at this critical time, a collaborative global effort is needed to scale up of vaccine manufacturing and speed-up vaccine roll-outs to minimize further risks. Also, a continuous genetic monitoring to track and identify mutants of concerns is required to ensure global safety.

\section{Conflict of Interest}

All authors declare no conflict of interest.

\section{Bibliography}

1. Berber E., et al. "Could targeting immunometabolism be a way to control the burden of COVID-19 infection?" Microbes and Infection 23.2 (2021): 104780.

2. WHO. "Novel Coronavirus (2019-nCoV)" (2020).

3. Nippon. "Coronavirus Cases by Country" (2021).

4. Lu R., et al. "Genomic characterisation and epidemiology of 2019 novel coronavirus: implications for virus origins and receptor binding". Lancet 395.10224 (2020): 565-574.

5. Shereen MA., et al. "COVID-19 infection: Emergence, transmission, and characteristics of human coronaviruses". Journal of Advanced Research 24 (2020): 91-98. 
6. Esakandari H., et al. "A comprehensive review of COVID-19 characteristics". Biological Procedures Online 22 (2020): 19.

7. Shah VK., et al. "Overview of Immune Response During SARSCoV-2 Infection: Lessons From the Past”. Frontiers in Immunology 11 (2020): 1949.

8. Sterlin D., et al. "IgA dominates the early neutralizing antibody response to SARS-CoV-2". Science Translational Medicine 13.577 (2021): eabd2223.

9. Wheatley AK., et al. "Evolution of immune responses to SARSCoV-2 in mild-moderate COVID-19". Nature Communications 12.1 (2021): 1162.

10. Herold T., et al. "Level of IL-6 predicts respiratory failure in hospitalized symptomatic COVID-19 patients”. medRxiv (2020): 2020.04.01.20047381.

11. VanPatten S., et al. "Evidence supporting the use of peptides and peptidomimetics as potential SARS-CoV-2 (COVID-19) therapeutics". Future Medicinal Chemistry 12.18 (2020): 16471656.

12. Saurabh S and Purohit SS. "A Modified ACE2 peptide mimic to block SARS-CoV2 entry". bioRxiv (2020): 2020.05.07.082230.

13. Chien M., et al. "Nucleotide Analogues as Inhibitors of SARSCoV-2 Polymerase, a Key Drug Target for COVID-19". Journal of Proteome Research 19.11 (2020): 4690-4697.

14. Ardestani A and Azizi Z. "Targeting glucose metabolism for treatment of COVID-19". Signal Transduction and Targeted Therapy 6.1 (2021): 112.

15. Lokugamage KG., et al. "SARS-CoV-2 is sensitive to type I interferon pretreatment". bioRxiv (2020).

16. Sallard E., et al. "Type 1 interferons as a potential treatment against COVID-19”. Antiviral Research 178 (2020): 104791.

17. Zhou Q., et al. "Interferon- $\alpha 2 b$ Treatment for COVID-19". Frontiers in Immunology 11 (2020): 1061.

18. Hung IF., et al. "Triple combination of interferon beta-1b, lopinavir-ritonavir, and ribavirin in the treatment of patients admitted to hospital with COVID-19: an open-label, randomised, phase 2 trial". Lancet 395.10238 (2020): 1695-1704.
19. Huang Q., et al. "Targeting inflammation and cytokine storm in COVID-19”. Pharmacological Research 159 (2020): 105051.

20. Ledford H. "Coronavirus breakthrough: dexamethasone is first drug shown to save lives". Nature 582.7813 (2020): 469.

21. Tang Y., et al. "Cytokine Storm in COVID-19: The Current Evidence and Treatment Strategies". Frontiers in Immunology 11 (2020): 1708.

22. de Wilde AH., et al. "Cyclosporin A inhibits the replication of diverse coronaviruses". Journal of General Virology 92 (2011): 2542-2548.

23. Funk CD., et al. "A Snapshot of the Global Race for Vaccines Targeting SARS-CoV-2 and the COVID-19 Pandemic". Frontiers in Pharmacology 11.937 (2020).

24. Kruse RL. "Therapeutic strategies in an outbreak scenario to treat the novel coronavirus originating in Wuhan, China". F1000Reserach 9 (2020): 72.

25. Amanat F and Krammer F. "SARS-CoV-2 Vaccines: Status Report”. Immunity 52.4 (2020): 583-589.

26. Wang Q., et al. "Immunodominant SARS Coronavirus Epitopes in Humans Elicited both Enhancing and Neutralizing Effects on Infection in Non-human Primates". ACS Infectious Diseases 2.5 (2016): 361-376.

27. WHO. COVID-19 vaccine development (2020).

28. Sasso E., et al. "New viral vectors for infectious diseases and cancer". Seminars in Immunology 50 (2020): 101430.

29. van Doremalen N., et al. "ChAdOx1 $\mathrm{nCoV}-19$ vaccination prevents SARS-CoV-2 pneumonia in rhesus macaques". bioRxiv: The Preprint Server for Biology (2020): 2020.05.13.093195.

30. WHO. "DRAFT landscape of COVID-19 candidate vaccines" (2020).

31. Mirzaie A., et al. "A narrative literature review on traditional medicine options for treatment of corona virus disease 2019 (COVID-19)". Complementary Therapies in Clinical Practice 40 (2020): 101214.

32. Luo H., et al. "Reflections on treatment of COVID-19 with traditional Chinese medicine". Chinese Medicine 151 (2020): 94. 
33. Xiong X., et al. "Chinese herbal medicine for coronavirus disease 2019: A systematic review and meta-analysis". Pharmacology Research 160 (2020): 105056.

34. Gomathi M., et al. "Drug Studies on Rett Syndrome: From Bench to Bedside". Journal of Autism and Developmental Disorders 50.8 (2020): 2740-2764.

35. Golechha M. "Time to realise the true potential of Ayurveda against COVID-19". Brain, Behavior, and Immunity 87 (2020): 130-131.

36. Vimalanathan S., et al. "Medicinal plants of Tamil Nadu (Southern India) are a rich source of antiviral activities". Pharmaceutical Biology 47.5 (2009): 422-429.

37. Heidary F., et al. "The Potential Use of Persian Herbal Medicines Against COVID-19 Through Angiotensin-Converting Enzyme 2". Archives of Clinical Infectious Diseases 15 (2020): e102838.

38. Ziai S., et al. "Inhibitory Effects of Germinal Angiotensin Converting Enzyme by Medicinal Plants Used”. Iranian Traditional Medicine as Antihypertensive 16 (2009): 134-143.

39. Hemilä H., et al. "Vitamin C and acute respiratory infections". The International Journal of Tuberculosis and Lung Disease : The Official Journal of the International Union against Tuberculosis and Lung Disease 3 (1999): 756-761.

40. Mercatelli D and Giorgi FM. "Geographic and Genomic Distribution of SARS-CoV-2 Mutations". Frontiers in Microbiology 11.1800 (2020).

41. Wibmer CK., et al. "SARS-CoV-2 501Y.V2 escapes neutralization by South African COVID-19 donor plasma". bioRxiv (2021): 2021.01.18.427166.

42. Edara V-V., et al. "Infection and vaccine-induced neutralizing antibody responses to the SARS-CoV-2 B.1.617.1 variant". bioRxiv (2021): 2021.05.09.443299.

43. Chatterjee B., et al. "The mortality due to COVID-19 in different nations is associated with the demographic character of nations and the prevalence of autoimmunity". medRxiv (2020): 2020.07.31.20165696.

44. Tiwari BK and Khosa R. "Hepatoprotective and antioxidant effect of Sphaeranthus indicus against acetaminophen-induced hepatotoxicity in rats". Journal of Pharmaceutical Sciences and Research 1.2 (2009): 26-30.

45. Keyaerts E., et al. "In vitro inhibition of severe acute respiratory syndrome coronavirus by chloroquine". Biochemical and Biophysical Research Communications 323.1 (2004): 264-268.

46. Hussain F., et al. "Identification of Hypotensive Biofunctional Compounds of $<\mathrm{i}>$ Coriandrum sativum $</ \mathrm{i}>$ and Evaluation of Their Angiotensin-Converting Enzyme (ACE) Inhibition Potential". Oxidative Medicine and Cellular Longevity 2018 (2018): 4643736.

\section{Volume 4 Issue 8 August 2021}

(c) All rights are reserved by Suresh Thakur., et al. 